\title{
Effect of wetting-drying cycles on surface cracking and swell-shrink behavior of expansive soil modified with ionic soil stabilizer
}

\author{
Huan Minh Dao *, Anh Thuc Thi Nguyen, Tuan Manh Do \\ Faculty of Geology, Hanoi University of Natural Resources and Environment, Hanoi, Vietnam
}

\section{ARTICLE INFO \\ Article history: \\ Received 21 $1^{\text {st }}$ Sept. 2020 \\ Revised 23rd Nov. 2020 \\ Accepted 31 st Dec. 2020}

Keywords:

Crack,

Swell-shrink behavior,

Treated expansive soil,

Wetting-drying cycles.

\section{ABSTRACT}

This paper presents the results of an experimental investigation of the effect of wetting-drying cycles on the surface cracking and swell-shrink behavior of modified expansive soils. An image processing technique was employed to understand this effect by quantifying the surface crack area density, crack number, crack length, mean crack width, and absolute shrinkage. Parameters such as height, the relative rate of expansion, and linear shrinkage were used to characterize the effect of wetting-drying cycles on the swell-shrink behavior of the specimens subjected to various overburden pressures. The results showed that the increase in the number of wetting/drying cycles accelerated the crack growth and led to the increased crack number, total crack length, and surface crack area density. Moreover, as the number of wetting/drying cycles increased, the absolute shrinkage to be on the rise, and the mean crack width exhibited fluctuation characteristics. Furthermore, the moisture content was inversely related to the crack extent. For the specimens subjected to various overburden pressures, the height and the moisture content showed a good linear relationship. With the increase in wetting/drying cycles, the relative rate of expansion of the specimen decreased. Additionally, a larger overburden pressure resulted in a lower relative rate of expansion; however, as the number of wetting/drying cycles increased, the relative rate of linear shrinkage increased and then decreased.

Copyright (C) 2020 Hanoi University of Mining and Geology. All rights reserved.
${ }^{*}$ Corresponding author

E-mail: dmhuan@hunre.edu.vn DOI: 10.46326/JMES.2020.61(6).01

\section{Introduction}

Expansive soil is a naturally occurring ground that can interact with water and therefore changes in volume and structure occur (Сорочан, 1982). It is mainly constituted of strongly hydrophilic clay minerals such as montmorillonite (smectite), 
illite, palygorskite, and kaolinite (Al-Rawas and Goosen, 2006). The presence of montmorillonite clay in these soils imparts its high swell-shrink potentials (Chen, 2006). Therefore, it is a kind of soil that expands and softens when water is absorbed whereas it shrinks and cracks when water dries out. Due to these characteristics, expansive soils have worldwide problems (Erguler and Ulusay, 2003). For example, the estimated damage to buildings, roads, and other structures built on expansive soils exceeds 15 billion dollars in the Usannually (Al-Rawas and Goosen, 2006). Such soils are considered natural hazards that pose challenges to civil engineers, construction firms, and enterprise owners. Principally, swelling occurs when water infiltrates between the clay particles, causing them to separate. Researchers have made several attempts to obtain the swelling or shrinkage characteristics of the expansive soils. Some progress has been made toward characterizing the swelling and shrinkage characteristics, despite the complexity of behavior (Boivin et al., 2006; Cornelis et al., 2006; Rao et al., 2004; Nayak and Christensen, 1971).

Some scholars also conducted studies on the effect of moisture on surface cracking. Lu et al. (2002) investigated the crack evolution of Nanyang remolded expansive soil during wettingdrying cycles using computerized tomography (CT). From the CT data, they defined a crack damage variable and analyzed its relationship with the soil's accumulative drying volume. Yuan and Yin (2004) proposed the gray level entropy as an index to measure and evaluate the development extent of the cracks in the expansive soils. Tang et al. (2007) employed an image processing technique to quantitatively analyze and describe the structural and geometric characteristics of cracks in clay during the process of drying and shrinkage. Li et al. (2009) used the image processing technique to analyze the relationship between the cracks' fractal dimension in the expansive soils and the crack density. Zeng et al. (2013) utilized mercury intrusion porosimetry (MIP) to study the changes of the pore in expansive soil during wettingdrying cycles. The results showed that the microstructural parameters of expansive soil increased with the rising number of wetting/drying cycles, such as the total volume of the pores, the porosity, and the average pore diameter. Zhang et al. (2011) carried out laboratory wetting-drying tests on Nanyang expansive soil to investigate the crack evolution characteristics. The vector diagram technology was employed to characterize the crack photos to extract its geometric features. The effect of structural damage on yielding characteristics of the expansive soils investigated the microstructure changes of the soil immersed in water and subject to wetting-drying (Yao Zhihua et al., 2010; Yao Zhihua et al., 2010). Tang et al. (2012) established a sound theory for characterizing desiccation cracking in a study on desiccation cracking behavior of expansive soil. . Yang et al. (2006) carried out an experimental study to reveal the effect of wetting-drying cycles on the expansive soil's strength and deformation characteristics under load and obtained the strength changing factors. Kishné et al. (2010) studied the temporal dynamics in surface cracking of a Vertisol, emphasizing the analysis of the relationship of antecedent soil moisture before cracking and long-term weather variations with cracking densities. Pires et al. (2005) used $\alpha$ ray computed tomography as a tool to investigate possible modifications in soil structure induced by wetting/drying cycles and to analyze how these alterations can affect soil water retention.

From the literature reviewscholars mainly focused on the swell-shrink behavior of undisturbed soils or remolded soils, with little notice to the swell-shrink behavior of expansive soils modified with ionic soil stabilizer (ISS). Some studies focused only on the mechanisms of soil stabilization with ionic stabilizer. For example, Katz et al. (2001) studied comprehensively to reveal the underlying mechanism of the liquid ionic stabilizer to the soil. However, quite a few studies were dedicated to investigating the surface cracking and swell-shrink behavior of expansive soil modified with ISS. Therefore, this study carried out laboratory wetting/drying tests on expansive soil modified with ionic soil stabilizer (ISS). An image processing technique was employed to aid the understanding of the effect of wetting-drying cycles on the cracking and swell-shrink behavior of the modified soils by quantifying five measurement indexes including 
surface crack area density, crack number, total crack length, mean crack width, and absolute shrinkage (ratio or percentage). The five indexes were used to characterize the geometric and structural morphology of the surface cracks of the specimen. The five indexes help quantify the effect of the number of wetting-drying cycles on surface cracking. This research methodology can simulate the surface cracking behavior of modified expansive soil subjected to wetting-drying induced by rainfall infiltration. In addition, there were several attempts for investigation the effect of overburden stress on swell-shrink behavior of the treated soils. The research results can provide a basis for the study of the stability of modified soil.

\section{Microscopic spherical particle model for expansive soil}

Expansive soil is mainly made of soil particles, air, and water. Soil is saturated when it has reached its maximum water content; otherwise, it is unsaturated. In essence, the wetting-drying cycle of the expansive soil is a reciprocal transformation process: the soil changes from the unsaturated condition to the saturated condition and vice versa. During this process, parallel with the strong dynamic coupling occurance among water, matrix suction, stress, deformation, and strength, the soil's pore structure, particle arrangement, and particle contact form change. As the moisture in soil dissipates and the soil reabsorbs water, the physical properties of the expansive soil changes accordingly. Figure 1 schematizes the ideal noncontact spherical particle model for the expansive soil. Since such forces as surface tension, water pressure $u_{w}$, and air pressure $u_{a}$ must reach an equilibrium state in the horizontal direction, we obtain:

$$
\begin{gathered}
u_{a}-u_{w}=T_{s}\left(1 / r_{1}-1 / r_{2}\right) \\
D=\left(r_{1}+r_{2}\right) \tan \alpha-R
\end{gathered}
$$

Where $u_{a}$ and $u_{w}$ separate the air pressure and water pressure in the soil; $u_{a}-u_{w}$ stands for the matrix suction; $T_{s}$ is the surface tension, which is related to the factors such as specific material composition and temperature; $r_{1}$ and $r_{2}$ are the spherical radius of the ideal water body between the soil particles; $D$ is a half of the distance between the soil particles; $\alpha$ is the contact angle between the soil particle and the water body; and $R$ is the radius of the spherical soil particle (Figure 2).

During wetting-drying cycles, water loss and water adsorption directly manifest the changes and merging of the water body between particles. Water loss and water adsorption can directly induce cracks in the soil. Due to high moisture content, the soil particles are encased by a relatively thick water film, which increases the distance between the soil particles. In the drying process, moisture leaves the soil gradually in evaporation, leading to a decrease in moisture content and water film thickness. However, as the moisture dissipates, the matrix suction increases. The soil particles rearrange themselves and approach each other as a subject to the suction force. Therefore, pores gradually become narrow. This is the underlying reason for the volume shrinkage of the expansive soil during the drying process.

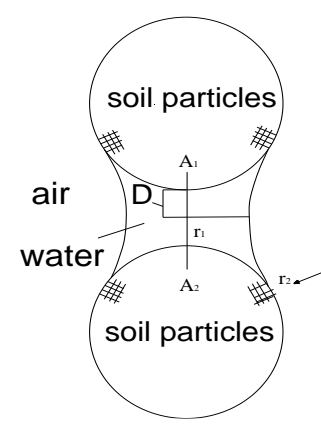

Figure 1. Ideal non-contact spherical particle model.

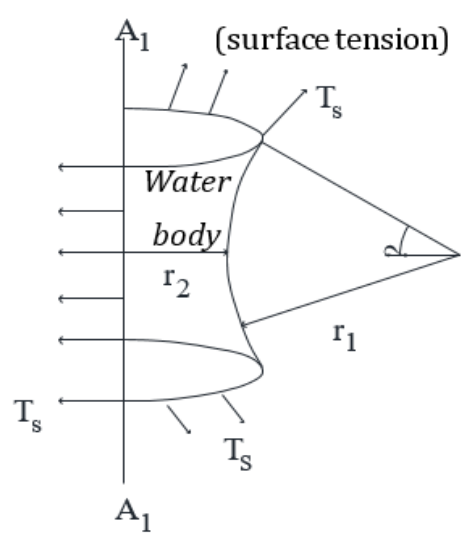

Figure 2. Force diagram for water body between the particles. 
The root causes for crack development in the expansive soil are: 1) the intrinsic tensile strength is not large enough to withstand the external load, 2) the discontinuous deformation occurring between adjacent particles leads to the fracturing or failure of the aggregate formed by the assembly of the particles. The reasons for crack development can be expressed by equations (3) and (4).

$$
\begin{gathered}
{\left[\begin{array}{l}
{[\sigma]<\sigma_{\text {tensile stress, }}} \\
{[\sigma]=\sigma_{\text {tensile stress, }}} \\
{[\sigma]>\sigma_{\text {tensile stress, }}}
\end{array}\right.} \\
{[\sigma]_{\text {tensiles stress }}=K \times\left(u_{a}-u_{w}\right)} \\
=K \times T_{s} \times\left(\frac{1}{r_{1}}-\frac{1}{r_{2}}\right)
\end{gathered}
$$

The above equations are based on the assumption below: internal cracks occurwhen the tensile stress acting on the aggregate is larger than or equal to the shear strength. Otherwise, internal cracks cannot develop. In Equation (4), $K$ stands for the essential factor influencing the tensile stress. Its magnitude is related to intermolecular interaction, Vander Waals force, and the electrostatic interaction between ions with opposite charges or ions with the same tasks.

The decrease in the moisture content destroys the original balance; the increase of the matrix suction is to resist the reduction of the moisture content to maintain the balance. Therefore, the matrix suction exerts its maximum capacity to restrict the moisture content from decreasing.

Through respective derivation, Equation (1) can be transformed into Equation (5). The moisture content varies the matrix suction changes at a maximum rate that resists the changes of the moisture content.

$$
\left\{\begin{array}{l}
\frac{\partial\left(u_{a}-u\right)}{\partial_{r_{1}}}=-\frac{T_{s}}{r_{1}^{2}} \\
\frac{\partial\left(u_{a}-u\right)}{\partial_{r_{2}}}=-\frac{T_{s}}{r_{2}^{2}}
\end{array}\right.
$$

\section{Material and Methods}

\subsection{Description of the study area}

The study area is Henan province, in which the data are collected during the geotechnical investigation process of the South-to-North Water Diversion Middle Route Phase I Project in Anyang section, China (Figure 3). The province has a total water supply of 2202.5 billion $\mathrm{m}^{3}$. In the Anyang section of the main canal, soft rock hills are distributed alternately with alluvial-diluvial inclined plain. The soft rock hills are mainly distributed in the areas from Princess's camp to $\mathrm{Du}$ Jia 'an and from the north of Anyang River to Honghe Tun. Alluvial-diluvial inclined plain is distributed among soft rock hills and mainly consists of alluvial-diluvial fans of Honghe, Anyang, and Zhanghe rivers. The terrain generally leans to the east and transitions to the North China Plain. The ground's elevation is $80.0 \div 105.0$ $\mathrm{m}$, and the slope is large near the hilly area, with a pitch of $6 \div 10 \%$ o. The downward slope is gently slow, with a slope of $3 \div 5 \%$ o.

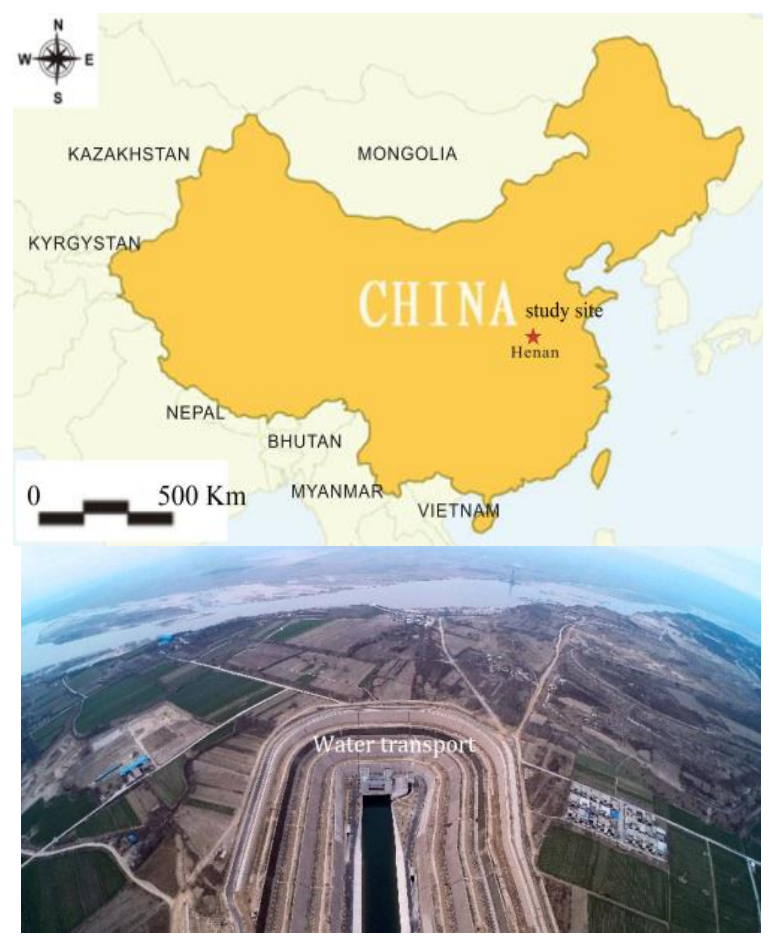

Figure 3. Study area, the Anyang section Henan province, China.

\subsection{Soil sample collection and processing}

Field investigations were carried out in August 2015. The expansive soils for the experiment was taken from a section of the main channel of the South-to-North Water Diversion Middle Route Phase I Project in Anyang section 
Henan province, China. The expansive covered soils were more compacted and maintained good integrity and stability. However, for the uncovered, those were poor in integrity and stability. The uncovered expansive soils are easy to disintegrate and quickly turn to crumby soil once disturbed regarding natural weathering.

Being subject to the influence of weathering for a period of time, the expansive soil was from the marlstone and claystone's surface layers. The weathered expansive soil is shown in Figure 4. It was worth noting that the parent rock structure of the expansive soil was almost damaged, and the mineral composition changed significantly. It is very close to "soil" in terms of its structural and strength characteristics. Therefore, this expansive soil has significant swell-shrink potential during wetting-drying cycles. The test was carried out on the undisturbed expansive soil to obtain its physical properties, listed in Table 1.

In a natural environment, the main channel's expansive soil has undergone repeated swell and shrink induced by rainfall and evaporation. The repeated swell-shrink destroyed its integrity, weakened its structural strength, and reduced its bearing capacity. Therefore, the repeated swellshrink accelerates the instability of the main

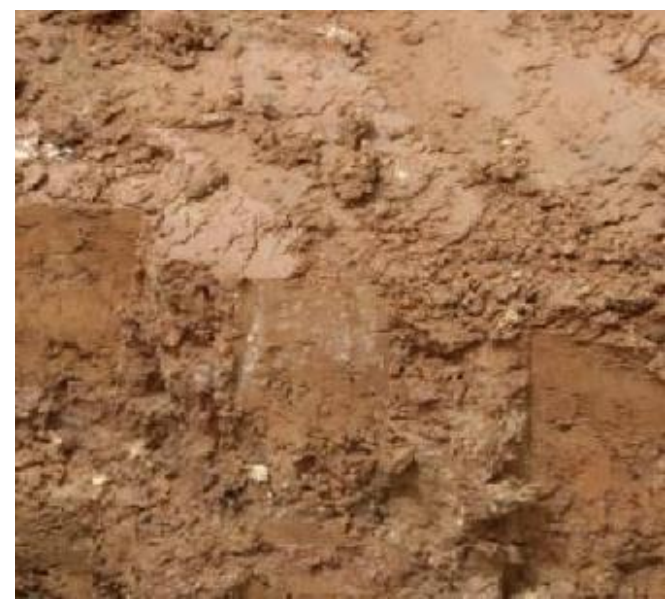

a. Brown red claystone expansive soil. channel's slope, which could cause geological hazards. An ionic soil stabilizer(ISS) that can improve the swell-shrink characteristics of the expansive soil and increase its bearing capacity was developed to mitigate the possible hazards. This ISS was used to prepare the experimental material.

The experimental material preparation is detailed as: multiple soil samples were weighed and spread the samples on each disc. The matching ratio of the ionic soil stabilizer and the soil sample was determined. The corresponding amount of ionic soil stabilizer was prepared for each soil sample. The ISS was sprayed over each soil sample layer by layer to ensure the even mixing of the ISS and the soil. Each soil sample was encapsulated with the fresh-keeping membrane, which was placed in the moisture retention tank for at least one week to ensure the full interaction of the ISS and the soil. According to different test requirements, determine whether to screen the samples or compact the samples into the test specimens. Samples were dried in the oven and then crushed into powder. The soil powder was screened with a sieve of $1 \mathrm{~mm}$ pore size. The proper amount of water was added into the soil powder and then thoroughly mixed up.

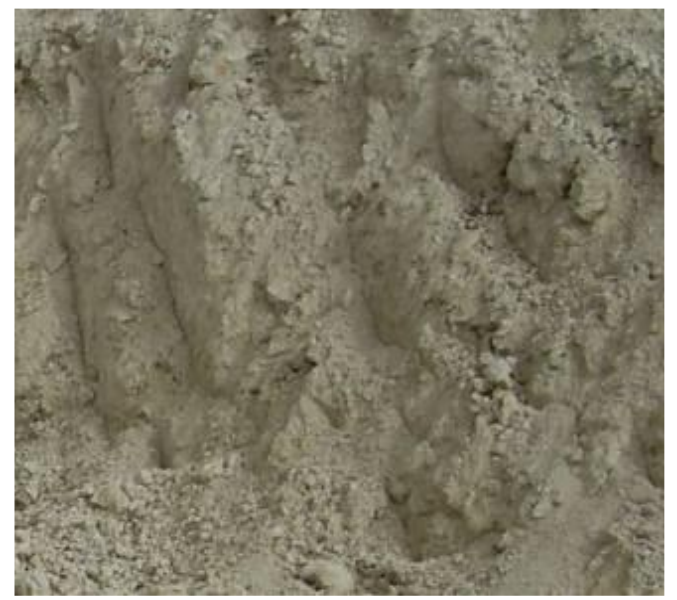

b. Marlstone expansive soil.

Figure 4. Weathered expansive soil at the study site.

Table 1. Physical properties of the expansive soil.

\begin{tabular}{|c|c|c|c|c|c|c|c|}
\hline $\begin{array}{c}\text { Initial } \\
\text { moisture } \\
\text { content/\% }\end{array}$ & $\begin{array}{c}\text { Natural } \\
\text { density } \\
/ \mathrm{g} . \mathrm{cm}^{-3}\end{array}$ & $\begin{array}{c}\text { Specific } \\
\text { gravity }\end{array}$ & $\begin{array}{c}\text { Liquid } \\
\text { limit/\% }\end{array}$ & $\begin{array}{c}\text { Plastic } \\
\text { limit/\% }\end{array}$ & $\begin{array}{c}\text { Plasticity } \\
\text { index }\end{array}$ & $\begin{array}{c}\text { Optimum moisture } \\
\text { content /\% }\end{array}$ & $\begin{array}{c}\text { maximum dry } \\
\text { density/g.cm }\end{array}$ \\
\hline 20.4 & 2.02 & 2.76 & 60.4 & 26.9 & 33.5 & 22.45 & 1.62 \\
\hline
\end{tabular}


The initial moisture content was controlled at $20 \%$. The soil powder was encapsulated with a plastic bag for at least $48 \mathrm{~h}$ to ensure the even distribution. Proper soil powder was weighed and poured into the cutting-ring sampler (cylindershaped vessel). The soil powder was compacted with the jack.

The test specimen was $61.8 \mathrm{~mm}$ in diameter and $20 \mathrm{~mm}$ in height. The initial dry density and initial saturation ratio were $1.3 \mathrm{~g} / \mathrm{cm}^{3}$ and $48.15 \%$, respectively.

\subsection{Experimental method}

Unified regulation for the wetting-drying experiment on expansive soil has not been issued. Therefore, refer to ASTM D4843-1988 (ASTM, 1988) for relevant procedures for dry and wet cycle tests. According to the specification requirements, seven $\Phi=61.8 \mathrm{~mm}, h=20 \mathrm{~mm}$ parallel cylindrical specimens.

Considering the test scenario designed by the predecessors, the number of wetting-drying cycles was determined as three. During the drying process, seven moisture contents were selected as the recording points: $35,30,25,20,15,10$, and $5 \%$. A high-resolution digital camera was well placed in front of the testing specimen to capture the photos.

The experimental process is detailed below: the prepared specimen was placed in a sealed container and dried at room temperature $(22 \pm 3$ $\left.{ }^{\circ} \mathrm{C}\right)$; the sample was weighed at a fixed interval and calculated the moisture content according to the changes of the weight. The specimen was photographed when the moisture content reached the above recording points; the example was replaced into the cutting-ring sampler when the moisture content came 5\% (deemed drying completely in this study). Filter paper and porous stone were placed at the top and bottom of the specimen and used fixtures to secure them. The model was immersed in water and took it out for moisture measurement at a fixed interval. The sample was stopped dipping into the water once the moisture content reached $35 \%$, and the photograph of the specimen was taken as 35\% was a recording point. The process was repeated twice.

\subsection{Digital Image Processing}

Digital image processing is to process the image by computers and convert the image signals into digital signals. The equipment needed for digital image processing includes cameras, digital image collectors (including synchronous controller, analog-digital converter, and frame memory), image processing computers, and image display terminals. The main processing task is completed through the image processing software. The obtained photos were of red, green, and blue (RGB) format color image. The difference between the cracks and the soil was only manifested in hue. Direct processing of these photos costs time. Besides, as the color images are extensive data, the process seems insufficient. To perform quantitative analysis on the surface cracks shown in these photos more efficiently and accurately, it needs tofollow processing procedures before further treatment:

Color images were converted into gray-level images. The grayscale was determined by the following formula: Gray $=(R+G+B) / 3$. After converting, the difference between the cracks and the soil was only manifested in a greyscale, which was conducive to further processing and analysis.

As there was a significant difference between the cracks and the soil in the greyscale, a greyscale threshold can be determined to transform these images further through binarization. The crack area will turn black as the greyscale is larger than the determined threshold; the remaining regions (the soil area) will turn white as the greyscale is smaller than the determined threshold. Therefore, the cracks are independently separated from the soil.

Due to the unevenness of the soil surface, some areas were misrepresented. For example, for the dark parts in the sample soil, some white zones that represent the soil were misrepresented after binarization. For the soil particles in the cracks, some isolated black dots that did not mean the cracksalso appeared wrong after binarization. Also, the white container bottom can also harm the binarization of the images as the whiteness can be projected to the pictures through cracks, affecting the accuracy of the quantitative analysis. The images must be denoised for more precise practical work.

While maintaining the basic profile of the images, a thinning algorithm was employed to 
extract the skeleton of the cracks from binary photos to reduce the redundant information in the picture. As a result, the computation efficiency was improved significantly. It is worth noting that this process did not alter the basic profile of the cracks. Instead, it was more favorable to quantify the cracks' parameters, such as the crack length, crack width, and crack number.

As can be seen from Figure 5, in the first wetting-drying cycle, no apparent cracks were observed. Therefore, to reduce the workload, image processing and quantitative analysis were only performed on images photographed in the second and third wetting-drying cycles.

\subsection{Evaluation index used for quantitative analysis}

According to the cracks' morphological structure shown in the binary image, the following indexes were proposed to perform the quantitative analysis.

(1) Surface crack area density: This refers to the ratio of the crack area to the total area of the soil, which indicates its crack extent.

(2) Crack number: This is defined as the skeleton line between the node and the endpoint or the isolated skeleton line. This index characterizes the development extent of the cracks.
(3) Total crack length: This is defined as the summation of the length of all the skeleton lines.

(4) Mean crack width: This refers to the ratio of the total crack area to the full crack length, which is an indication of the stretching extent of the developed cracks.

(5) Absolute shrinkage: This is defined as the ratio of the reduced area to the original one:

$$
\left(D_{1}{ }^{2}-D_{2}^{2}\right) / D_{1}{ }^{2}
$$

Where, $D_{1}$ is the original diameter of the specimen and $D_{2}$ is the diameter of the specimen after shrinkage.

\section{Results and discussion}

\subsection{Quantitative analysis of the cracks}

After quantitative analysis, we plotted the quantitative results against the moisture content for specimen subject to different wetting-drying cycles. The curves are shown in Figure 6.

In Figure 6(a), two points (A and B) are outliers, which apparently deviate from the general trend of the line. The underlying reason for the apparent deviation is possibly related to the calculation method used to calculate the crack area. Figure 6(a) indicates that as the specimen dries, shrinking to its center as a whole, leading to the decrease of the crack width.

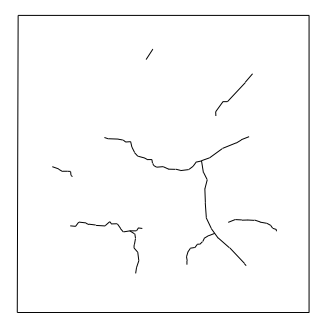

$1^{\text {st }}$ wetting-drying cycle - 5\% moisture content

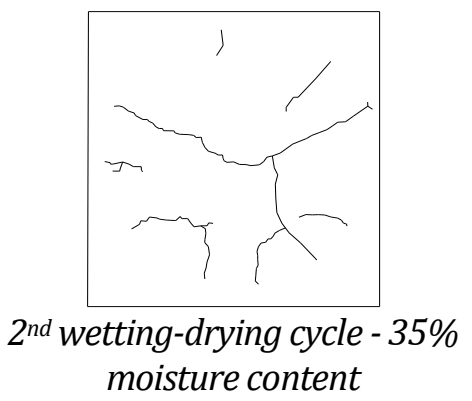

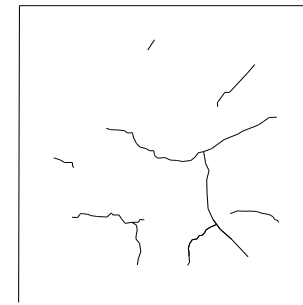

$1^{\text {st }}$ wetting-drying cycle - 35\% moisture content

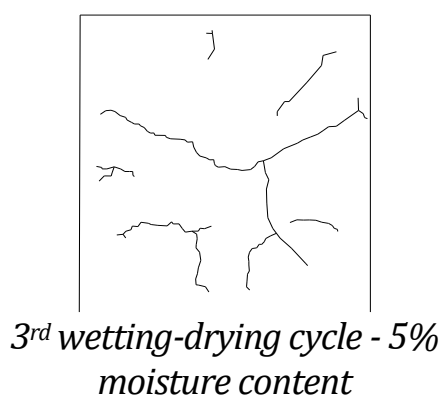

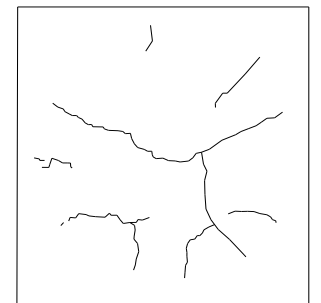

$2^{\text {nd }}$ wetting-drying cycle - $5 \%$ moisture content

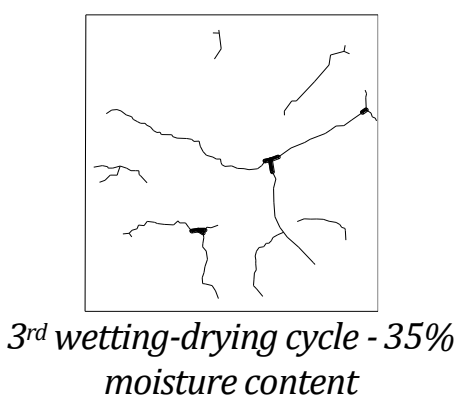

Figure 5. Crack images after treatment at the moisture content of 5\% and 35\%. 


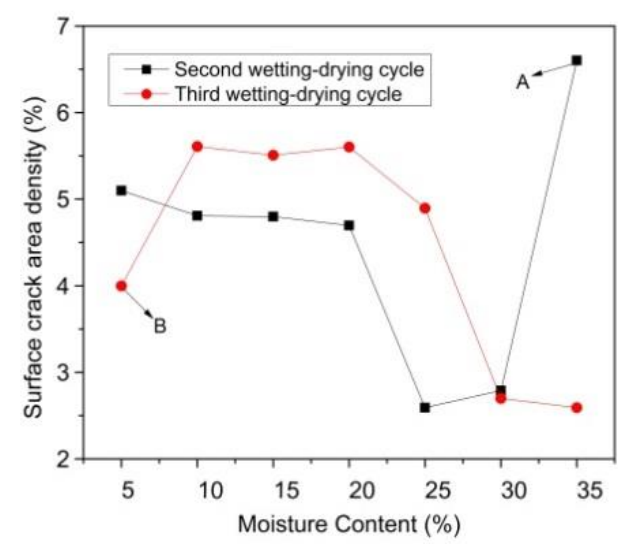

a. Surface crack area density versus moisture content during the second and third wetting-drying cycles.

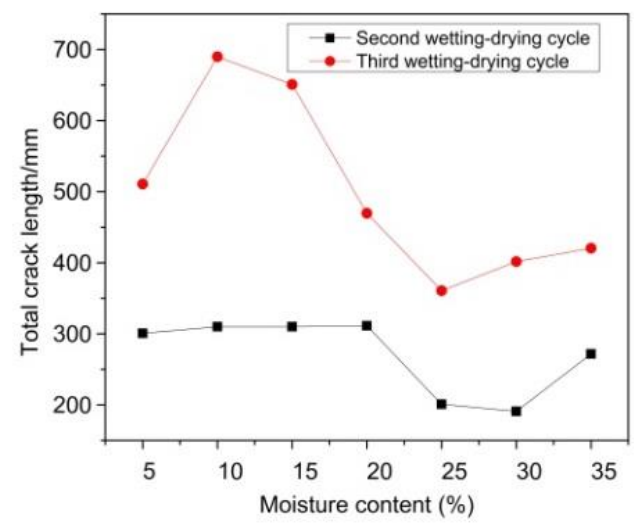

c. Total crack length versus moisture content during the second and third wetting-drying cycles.

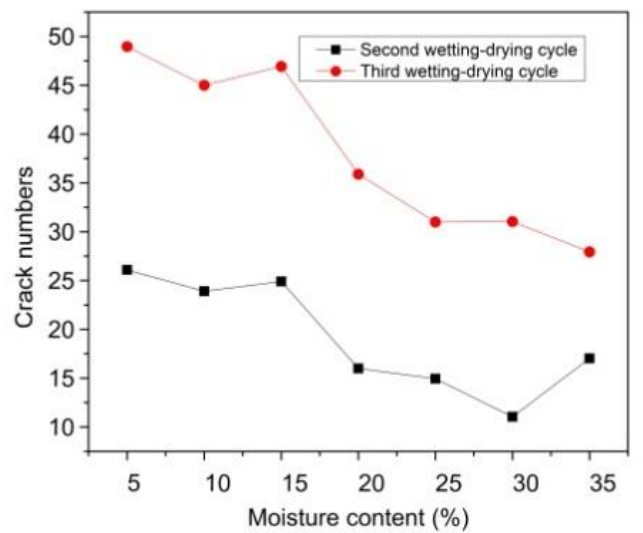

b. Crack numbers versus moisture content during the second and third wetting-drying cycles.

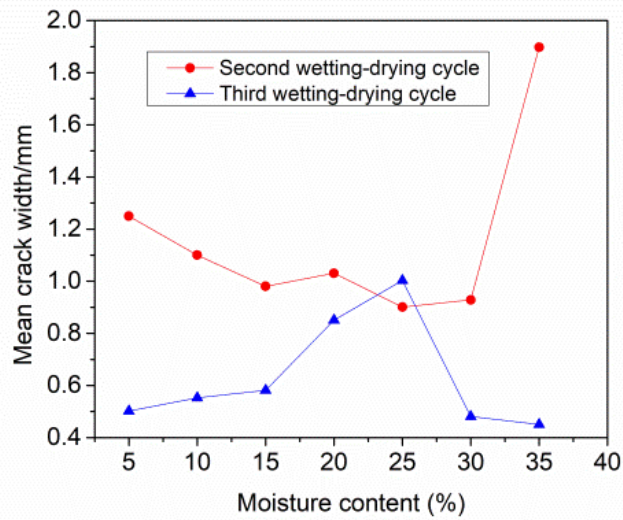

d. Mean crack width versus moisture content during the second and third wetting-drying cycles.

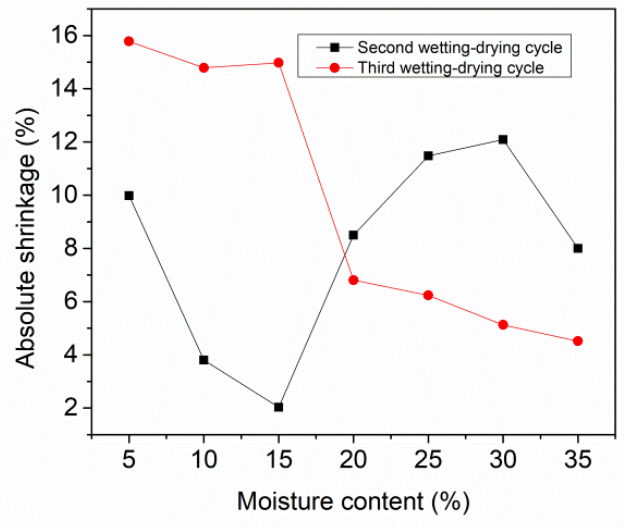

e. Absolute shrinkge versus moisture content during the second and third wetting-drying cycles.

Figure 6. Quantitative results for specimens subject to the second and third wetting-drying cycles. 
In the drying process, the surface crack area density in the third wetting-drying cycle is, in general, more significant than that in the second wetting-drying cycle. This demonstrates that as the number of wetting-drying cycles increases, cracks in the specimen undergo further development. In addition, with the decrease of the moisture content, the surface crack area density tends to grow. Therefore, the experimental results demonstrate that the number of wetting-drying cycles and the moisture content is the two primary factors that affect the cracking of the expansive soil, which co-affect the cracks' generation and development in the soil.

Figures $6(b, c)$ show that as the number of wetting-drying cycles increased, the crack and total crack length increased as well. During the third wetting-drying cycle, the crack number had an excellent linear relationship with the moisture content, with the coefficient of determination reaching 0.96 (shown in Figure 7). With the increase in the number of wetting-drying cycles, the crack number at each moisture content increased, increasing from $9 \div 23$ and increasing by $52 \div 190 \%$. During this process, the cracks in the specimen grow further, generating many secondary micro-fissures. Due to the further development of the original cracks and the generation of the secondary micro-cracks, the total crack length undergoes an apparent increase. Figure 6(d) shows that with the rise in the wetting-drying cycle, the mean crack width became narrow, which mainly due to the increase in the number of microcracks.

Figure 6(e) demonstrates that the absolute shrinkage during the third wetting-drying cycle

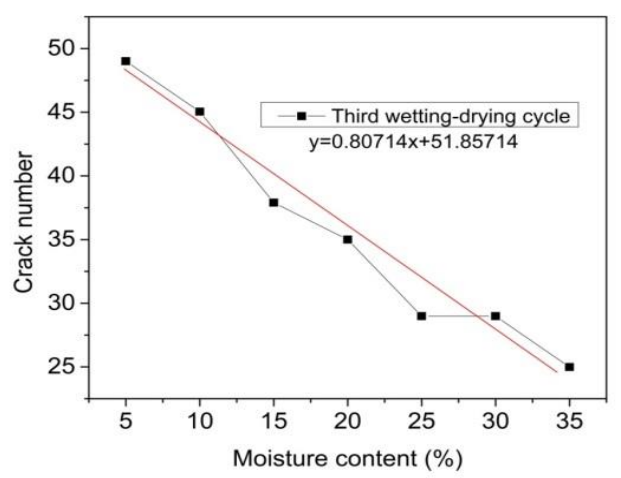

Figure 7. Crack number versus moisture content during the third wetting-drying cycle. exhibited outstanding changing characteristics. As the moisture content diminished, the absolute shrinkage increased. This activity indicates that the specimen shrinks to its center as it dried. During the second wetting-drying cycle, the absolute shrinkage exhibited significant fluctuation characteristics. However, as the moisture content decreased from 20 to $15 \%$, the absolute shrinkage also increased, showing similar changing features exhibited in the third wetting-drying cycle. In general, the absolute shrinkage in the third wetting-drying cycle was larger than that in the second one, which suggests that the specimen shrinks even further during the third wetting-drying cycle.

The soil-water characteristic curve characterizes the relation between the suction force and the moisture as the soil wets and dries, and the soil-water characteristic curves were not identical. In the middle, there exists a hysteresis loop. The soil-water characteristic curve varied with the wetting-drying cycle (Lu et al., 2002). As the suction force changes with the wetting-drying process, the soil's internal pressure and the particle structure changed.

The swell-shrink induced deformation in the wetting-drying cycles is not fully (Tang et al., 2012). The deformation can be divided into two types, namely reversible deformation, and irreversible deformation. For the modified expansive soil, the relative rate of volume expansion and volume shrinkage decrease as the number of the wetting-drying cycles increases. As mentioned before, the mean crack width in the second wetting-drying cycle was greater than that in the third one. This was due to the changes in the soil's internal structure and stress field as the expansive soil re-undergoes wetting and drying (Katz et al., 2001). The changes weaken the swellshrink performance in the wetting-drying cycle (Kalkan, 2011). Therefore, some of the cracks became narrow when the soil sample was saturated. As a result, the mean crack width was reduced. Besides, the decrease in soil volume and the soil restructuring can also narrow the cracks.

\subsection{Analysis of the swell-shrink characteristics}

Variation in composition and structure affects the swell-shrink characteristics of the expansive soil. For a specific expansive soil 
composed of the same material, its swell-shrink deformation is controlled mainly by the initial moisture content and maximum dry density, as well as the magnitude of the external force exerting on it. For the expansive soil subjected to various overburden pressures, its swell-shrink deformation is controlled mainly by the moisture content and the external force acting on it.

Figure 8 shows the changes in the specimen's height against the moisture content during the second wetting-drying cycle, as the specimen was subjected to various overburden pressures. Figure 8 show that the overburden pressure was 5 and $10 \mathrm{kPa}$, the height of the specimen showed an excellent linear relationship with the moisture content. Moreover, when the overburden pressure was $0 \mathrm{kPa}$, the relationship between the specimen's height and the moisture content presented some linear characteristics initially; however, as the moisture content decreased, some irreversible deformation occurred. For the expansive soil subject to various overburden pressures, its swell-shrink deformation is controlled mainly by the moisture content and the external force acting on it (Zhan, 2007). It indicated that the overburden pressure inhibited the swelling or expansion induced by water adsorption.

The mechanism underlying the above changing characteristics is given below. The existing theories, such as the electric double layer theory, concluded that the main reason for the expansion of the expansive soil after water absorption was due to the increase in the

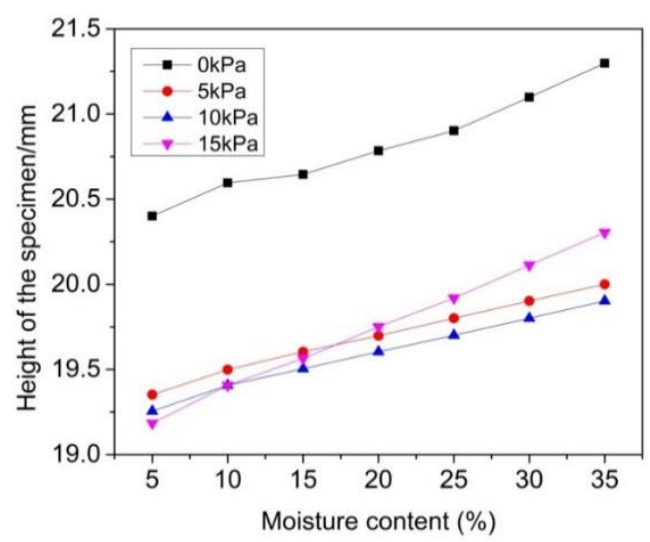

Figure 8. Changes in the specimen's height against the moisture content under various overburden pressures during the second wetting-drying cycle. thickness of the water film between the soil's crystal layers or particles (Bowers et al., 2018). As shown in Figure 1, the ideal non-contact spherical particle model, the water film distribution showed zoning characteristics. During the water loss/drying process, water contained in the space between the aggregates was the one that dissipated the first due to the attraction between the polar molecules or ions and the Van der Waals' force between the molecules. The dissipation of the water in the space resulted in a decrease in the thickness of the water film between the crystal layers. Its microscopic manifestation was due to the shrinkage of the expansive soil. After the water's dissipation, the ideal non-contact spherical particle model was reduced to an ideal contact spherical particle model. Then the bound water formed due to hydration began to dissipate. However, as there was no space between the aggregates, the bound water's dissipation did not cause the expansive soil's shrinkage anymore. It was consistent with the shrinkage experimental results: the expansive soil's shrinkage limit was the maximum shrinkage extent of the expansive soil when it dried.

Figures 9 and 10 show the changes in the relative rate of expansion and the relative rate of linear shrinkage against the number of the wetting-drying cycle as the specimen is subjected to various overburden pressures. Figures show that as the number of the wetting-drying process increased, the relative rate of expansion of the specimen under various overburden pressures all decreased gradually. The greater the overburden pressure, the smaller the relative rate of expansion, indicating that the overburden pressure inhibited the swelling or development induced by water adsorption. For the modified expansive soil that is not fully saturated, a smaller external force can have a more significant effect on its swelling characteristics. As the number of the wetting - drying cycle increased, the relative rate of linear shrinkage of the specimen under various overburden pressures all increased first and then decreased; the relative rate of linear shrinkage reached the peak value during the second wetting-drying cycle. The microscopic particle of the expansive soil aggregated into various parts, leaving pores in between. The pores' characteristic is one of the main factors 


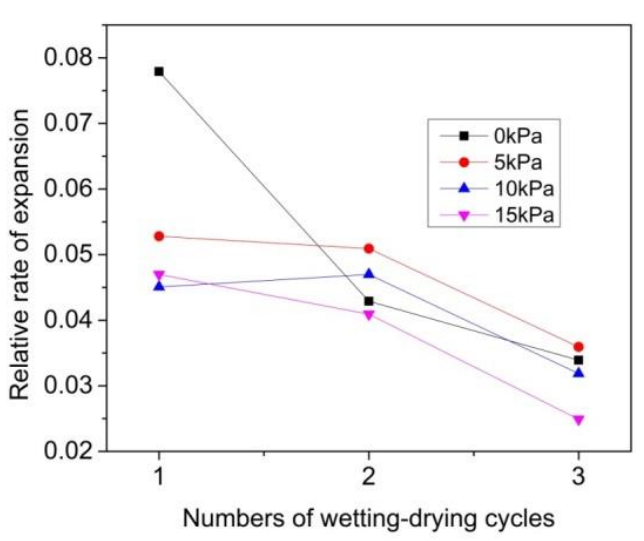

Figure 9. Changes in the relative rate of expansion against the number of the wetting-drying cycle as the specimen being subject to various overburden pressures.

that determine how the expansive soil behaves during shrinking and swelling (Hai-bo et al., 2009). As the soil absorbs water the first time, it expands, and the pores between the aggregates are filled by water. In the meantime, water film increases in thickness, resulting in the further swelling/expansion of the soil. Also, changes take place in the structural form between the aggregates. The aggregates can expand and undergo self-rotation due to the unbalanced force induced by water adsorption. As a result, the pore ratio of the expansive soil grows. During the water loss (drying) process, the free water contained in the space between the aggregates is the one that dissipates first, while in the meantime, tensile cracks begin to develop inside the soil. In the first wetting-drying cycle, the generated tensile cracks did not play a prominent role in swell-shrink deformation (Tang et al., 2016). However, a significant role was played in the second wettingdrying cycle as the generated tensile cracks coalesce and grow, destroying the soil's integral structure, causing a significant number of microcracks inside the aggregates. As a result, the strength of the soil decreases materially. This is further compounded by the overburden pressure, which results in the collapse of the aggregates. Therefore, in the second wetting-drying cycle, the swell-shrink deformation also involves the deformation induced by the aggregates' collapse. It explains the relative rate of linear shrinkage reaches the peak value in the second wetting-

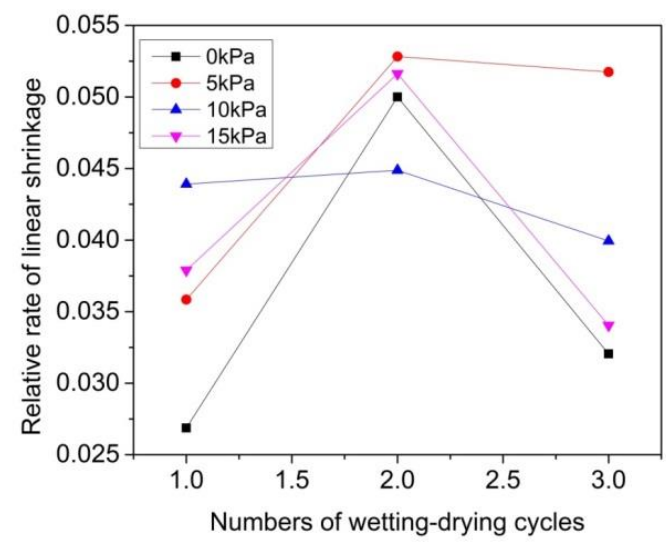

Figure 10. Changes in the relative rate of linear shrinkage against the number of the wettingdrying cycle as the specimen being subject to various overburden pressures.

drying cycle, and it reduces as the number of the wetting-drying cycle increases.

\section{Conclusions}

(1) The number of wetting-drying cycles affects the development of cracks in the modified expansive soil. As the number of the wettingdrying cycle increases, cracks develop profusely. In comparison with the second wetting-drying cycle, in the third wetting-drying cycle, the surface crack area density increases by $1 \%$, the crack number grows by $99 \%$, the total crack length increase by $85 \%$, the absolute shrinkage grows by $85 \%$, and the mean crack width expands by $83 \%$.

(2) During the drying of the modified expansive soil, the moisture content, in general, is inversely related to the crack extent. As the moisture content decreases, parameters like surface crack area density, crack number, total crack length, and absolute shrinkage increasing by $8 \%, 11 \%, 5 \%$, and $30 \%$, respectively, at each moisture content recoding point. However, the mean crack width, it changes irregularly as the overall swell-shrink of the specimen causes significant changes in the crack width.

(3) The modified expansive soil is overconsolidated and shows significant swell-shrink characteristics in the wetting-drying cycle. Cracks are easy to develop in the modified expansive soil. Also, it is a collapsible soil. Under high moisture 
content, under the overburden pressure, crack in the expansive soil closes and the soil undergoes significant restructuring. As the number of the wetting-drying cycle increases, the height of the specimen decreases. In comparison with the 5\% moisture content recording point at various overburden pressures, the specimen's height on average increases by about $1 \mathrm{~mm}$ at the $35 \%$ moisture content recording point.

(4) The overburden pressure has an inhibition effect on the modified expansive soil's swell-shrink characteristics. As the number of the wetting-drying cycle increases, more and more cracks develop in the expansive soil, which is accompanied by the occurrence of apparent macroscopic cracks and plane of failure and the material increase of the pore ratio. Compared with the first wetting-drying cycle, the relative rate of expansion in the third wetting-drying cycle reduces by $41 \%$. The repeated wetting-drying cycle has destroyed the specimen's internal structure, causing many cracks. When the moisture content reaches a certain level, and the overburden pressure is significant enough, the expansive soil would also undergo collapsible deformation after repeated wetting-drying.

\section{Acknowledgment}

This research did not receive any specific grant from funding agencies in the public, commercial, or not for profit sectors.

The author would like many thanks to Dr. Nguyen Thi Thuc Anh and Do Manh Tuan for English editing and comments. All these contributions have helped a lot to improve the quality of the paper.

\section{Conflict of interest}

All authors declare no conflict of interest.

\section{References}

Al-Rawas, A. A., Goosen, M. F., (2006). Expansive soils: recent advances in characterization and treatment. Taylor \& Francis.

American Society for Testing and Materials, ASTM D4843-1988, (1988). Standard test method for wetting and drying test of solid wastes[S]. Philadephta: ASTM Press.
Boivin, P., Garnier, P.,Vauclin, M., (2006). Modeling the soil shrinkage and water retention curves with the same equations. Soil science society of America journal 70(4), 10821093.

Bowers, G. M., Loring, J. S., Schaef, H. T., Walter, E. D., Burton, S. D., Hoyt, D. W., Kirkpatrick, R. J., (2018). Interaction of Hydrocarbons with Clays under Reservoir Conditions: In Situ Infrared and Nuclear Magnetic Resonance Spectroscopy and X-ray Diffraction for Expandable Clays with Variably Wet Supercritical Methane. ACS Earth and Space Chemistry.

Chen, F. H., (2006). Foundations on expansive soils (Vol. 12). Elsevier.

Cornelis, W. M., Corluy, J., Medina, H., Diaz, J., Hartmann, R., Van Meirvenne, M., Ruiz, M. E., (2006). Measuring and modelling the soil shrinkage characteristic curve. Geoderma 137(1-2), 179-191.

Erguler, Z. A., Ulusay, R., (2003). A simple test and predictive models for assessing swell potential of Ankara (Turkey) Clay. Engineering Geology 67(3-4), 331-352.

Hai-bo, Lu., Zhao-tian, Zeng., Yan-lin, Zhao., Hao, L., (2009). Experimental studies of strength of expansive soil in drying and wetting cycle. Rock and Soil Mechanics 30(12), 3797-3802.

Kalkan, E., (2011). Impact of wetting-drying cycles on swelling behavior of clayey soils modified by silica fume. Applied Clay Science 52(4), 345352.

Katz, L. E., Rauch, A. F., Liljestrand, H. M., Harmon, J. S., Shaw, K. S., \& Albers, H., (2001). Mechanisms of soil stabilization with liquid ionic stabilizer. Transportation Research Record 1757(1), 50-57.

Kishné, A. S., Morgan, C. L., Ge, Y., Miller, W. L., (2010). Antecedent soil moisture affecting surface cracking of a Vertisol in field conditions. Geoderma 157(3-4), 109-117.

Li, X. W., Feng, X., \& Zhang, Y., (2009). Depicting and analysis of expansive soil fissure in view of plane. Hydrogeology and Engineering Geology 1, 96-99. 
Lu, Z. H., Chen, Z. H., Pu, Y. B., (2002). A CT study on the crack evolution of expansive soil during drying and wetting cycles. Rock and Soil Mechanics-Wuhan 23(4; ISSU 78), 417-422.

Nayak, N. V., Christensen, R. W., (1971). Swelling characteristics of compacted expansive soils. Clays and Clay Minerals 19(4), 251 - 261.

Pires, L. F., Bacchi, O. O., Reichardt, K., (2005). Gamma ray computed tomography to evaluate wetting/drying soil structure changes. Nuclear instruments and methods in physics research section B: beam interactions with materials and atoms 229(3-4), 443-456.

Rao, A. S., Phanikumar, B. R., Sharma, R. S., (2004). Prediction of swelling characteristics of remoulded and compacted expansive soils using free swell index. Quarterly Journal of Engineering Geology and Hydrogeology 37(3), 217-226.

Tang, C. H., Shi, B., Liu, C., (2012). Study on desiccation cracking behavior of expansive soil. Journal of Engineering Geology 20(5), 663673.

Tang, C. S., Shi, B., Liu, C., Wang, B. J., (2007). Factors affecting the surface cracking in clay due to drying shrinkage. Journal of Hydraulic Engineering 10.

Tang, C. S., Wang, D. Y., Shi, B., Li, J., (2016). Effect of wetting-drying cycles on profile mechanical behavior of soils with different initial conditions. Catena 139, 105-116.

Yang, H. P., Zhang, R., Zheng, J. L., (2006). Variation of deformation and strength of expansive soil during cyclic wetting and drying under loading condition. Yantu Gongcheng Xuebao (Chinese
Journal of Geotechnical Engineering) 28(11), 1936-1941.

Yao Zhihua, Chen Zhenghan, Huang Xuefeng, et al., (2010). Influence of structural damage on yielding characteristics of expansive soils [J]. Chinese Journal of Rock Mechanics and Engineering 29(7), 1503-1512.

Yao Zhihua., Chen Zhenghan., Zhu Yuan-qing., Shiji, W., (2010). Meso-structural change of remolded expansive soils during wettingdrying cycles and triaxial soaking tests. Chinese Journal of Geotechnical Engineering 32(1), 6876.

Yuan, J. P., Yin, Z. Z., (2004). Quantitative index of fissure and strength characteristics of fissured expansive soils [J]. Journal of Hydraulic Engineering 6, 108-113.

Zeng, Z. T., Lu, H. B., Zhao, Y. L., Wang, Z. B., (2013). Study of pore size distribution of expansive soil during wetting-drying cycle and its application. Rock and Soil Mechanics 34(2), 322-328.

Zhan, L., (2007). Soil-water interaction in unsaturated expansive soil slopes. Frontiers of Architecture and Civil Engineering in China 1(2), 198.

Zhang, J. J., Gong, B. W., Hu, B., Zhou, X. W., Wang, J., (2011). Study of evolution law of fissures of expansive clay under wetting and drying cycles. Rock and Soil Mechanics 32(9), 27292734.

Сорочан. Е. A, (1982). Design and construction of buildings on expansive soil [M]. Beijing. China Building Industry Press. 